\title{
The Study on Service Design Development for Pharmacy Users: Using Smart Phone Application
}

\author{
Dong Min Lee ${ }^{1}$, Hye Jung Park², Dong In Lee ${ }^{3}$ \\ ${ }^{1}$ Department of Industrial Design, Kyung Hee University, Yongin, 446-701 \\ ${ }^{2}$ Smart Solution Lab, FEIT Creative Solution Group, Seoul, 137-267 \\ ${ }^{3}$ International Business of GPS, Kyung Hee University, Yongin, 446-701
}

\begin{abstract}
Objective: This study is to review the current state of services offered to pharmacy users, and develop a service design converging a prescription service and a smart phone application service in order to enhance patients' experience at pharmacies and home. Background: Under the new medical system; separation of prescribing and dispensing drugs, a doctor writes a prescription to their patients and patients have their prescription filled at the pharmacy. As the number of flue, allergy and atopy patients has increased, waiting lines have been longer at pharmacies. Besides, the current medical service system lacks of providing proper information on prescribed pills to patients. There are already services offered during waiting times such as offering free drinks, magazines or suggesting general drugs which you can buy without prescription, however they neither cover the current medical service's shorts nor shorten the waiting time. Method: I researched objective and perceived waiting times reduction methods, the current service status at pharmacies, and the government's policy direction in a medical service. Also, I observed a patient's journey from the hospital to pharmacy and then home. I examined the circumstance at pharmacies, patients' behaviors and their thoughts during their journey, and extracted three main goals to design a service in order to help patients have positive perception during the waiting time; (1) to reduce the perceived time by the way of visualizing time and offering readings about what patients consider necessary, (2) to educate patients what they are into and how to get through, (3) to establish trust among patients, doctors and pharmacists. Based on three goals, I designed a structure and a wireframe for a new service application of smart phones. Results: With a new service design for pharmacy users, users can track their medical record and visit the information about their current medical treatments anytime. Also the service helps patients build reliable relationships with doctors and pharmacists. Conclusion: Experience is not just an activity but series of multiple activities. The serving range of a medical service should not be determined by stakeholders but user's holistic experience. By approaching a service design with a holistic vision, it can enrich not only a temporary experience but also a whole life well being. Application: Since there are already many service applications advising patients about their illness and finding right doctors, this service design is focused on the experience from getting a prescription till feeling better. The next move is to combine those two parts medical services and design an integrated service application. As a prescription is going to be coded in numbers, we might consider to design an un-attended pharmacy which can shorten huge amount of time for filling prescriptions.
\end{abstract}

Keywords: Service design, Pharmacy users, Prescription, Waiting time, Smart phone application

Corresponding Author: Dong Min Lee. Department of Industrial Design, Kyung Hee University, Yongin, 446-701.

Mobile: 010-9072-1677, E-mail: mick@khu.ac.kr

Copyright@2012 by Ergonomics Society of Korea(pISSN:1229-1684 eISSN:2093-8462). All right reserved. 


\section{Introduction}

우리나라는 의약분업으로 2000년 7월부터 종합병원, 의 원, 보건소 등 모든 의료기관들이 외래환자들을 대상으로 조제하거나 투약을 할 수 없으며 약국에서는 의사의 처방전 없이 임의 조제나 전문 의약품 판매를 할 수 없게 되었다. 이에 따라 환자들은 병원에서 의사의 처방전을 받아 약국에 제출하여 약을 받아가게 되었으며, 국민건강보험의 건강보험 진료비 지급자료에 따르면 최근 5년간 진료받은 계절성 알 레르기 비염의 환자는 연평균 $14.5 \%$ 증가하였다. 또한 서 구화된 식생활과 환경 오염의 영향으로 아토피 피부염, 천식 등 환경 성 질환뿐만 아니라 당뇨, 디스크 환자도 연간 증가 하는 추세이다. 이에 따라 약국에서 처방전을 접수해 놓으 면 약사의 평균 조제시간은 4.7 분, 대기 인원 수와 장기투약 조제 또는 조제 난이도에 따라 길게는 15 분 이상도 기다릴 수 있다. "기다림"이라는 것은 소비자의 만족도에 상당히 큰 영향력을 미친다. 심한 경우, 줄을 서 기다리는 고객은 잠정 적으로 잃어버린 고객으로 분류하기도 한다. 현재 병원에서 는 Way finding system 및 번호표 제공 또는 문자 메시지 알림을 이용한 Service 제공 등 다양한 방법으로 대기시간 단축하여 사용자 만족도와 진료의 효율성을 동시에 높이고 자 노력하고 있다. 하지만 환자의 Journey는 병원에서 끝나 는 것이 아니라 의약분업에 의해 약국에서 약을 조제 받고 집에서 그 약을 복용하고 몇 번이 되던지 이 과정을 반복하 여 앓고 있는 병이 다 나아야지 끝나게 된다. 현 의료 서비 스 디자인은 총체적인 환자의 경험을 다루지 못하는 점을 지 적하며 본 연구에서는 환자 경험 중심의 시각으로 약국-약 복용-회복의 유기적 과정을 어우를 수 있는 의료 서비스 디 자인을 살펴보고자 한다.

\section{The Waiting Time}

\subsection{Visualizing the waiting time}

최근 은행, 영화관, 병원, 레스토랑 등에서는 번호표를 제 공하는 것이 보편화 되어서 대기 인원 수와 예상 대기시간 을 전광판으로 알려준다. 고객은 나의 차례가 다가오는 것을 시각적으로 확인하게 됨으로써 체감 대기시간을 단축시키고, '곧 내 차례다', '적게 기다려도 되겠다'와 같은 긍정적인 사고 를 하게끔 유도된다.

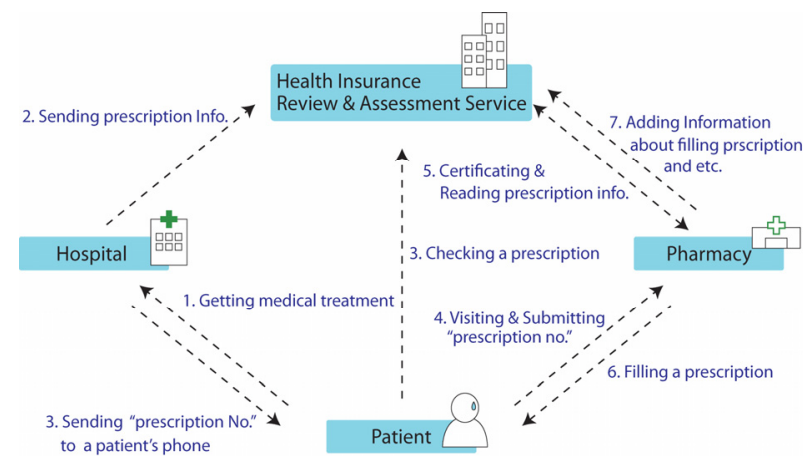

Figure 1. e-prescription communication flow

\subsection{Reducing the waiting time}

녹색성장위원회 보고대회에서 전자문서 사용률을 높이기 위해 종이 처방전 대신 휴대폰 등으로 처방전 번호를 받아 조제 처방을 받는 "e-처방 전달 시스템"을 발표하였다. 환자 는 병원에 가서 진료를 받으면, 진료 후 수납할 때 휴대폰으 로 처방전 번호가 포함된 문자 메시지를 받게 된다. 병원은 건강보험심사평가원으로 환자의 처방전 정보를 보내게 되고, 환자가 약국을 방문하여 처방전 번호를 제시하면 약국은 그 번호를 시스템에 입력하여 건강보험심사평가원으로부터 환 자의 처방전 정보를 받아 조제를 시작한다. 환자는 필요할 때 언제든지 건강보험심사평가원 시스템에 접속하여 자신의 처방전을 확인할 수 있다. 건강보험심사평가원은 2012년부 터 2013년까지 이 시스템을 구축하여 환자가 온라인으로 진료정보 교환을 할 수 있고, 병 - 의원 간 온라인 진료정보 교류를 활성화시키고자 한다. 이는 2015년까지 전국 500병 상 이상 대형병원으로 확대할 예정이다.

\subsection{Offering a task during the waiting time}

만일 기다리는 시간을 축소하거나 제거할 수 없다면, 그 기다리는 시간에 또 다른 가치를 부여하는 서비스를 제공하 여 고객의 집중을 시간의 흐름 이외의 활동으로 돌려 부정적 인 반응을 감소시킬 수 있다. 현재 병원에서는 진료 대기시 간에 고객 스스로가 할 수 있는 기초체력 검사; 시력검사, 체중, 혈압체크 서비스를 제공하고 있다. 이는 평소에 신경 을 쓰지 않고 있던 자신의 건강 상태를 체크하게 함으로써 자기 관리를 재인식시켜주며, 특정 증상으로 발견되지 않는 질병을 발견하게 되는 계기가 되기도 한다.

David H. Maister 교수는 The Psychology of Waiting Line(1985)라는 논문에 고객의 8가지 기다림에 대해 서술 하였다. 
1. 아무 것도 할 것이 없는 시간은 더 지겹다.

2. 일단 진행이 되면 덜 지겹다.

3. 불안하면 더 지겹다.

4. 무한정 기다리는 것은 더 지겹다.

5. 아무 이유 없이 기다리는 것은 더 지겹다.

6. 부당하다고 느끼면 기다리는 것은 더 지겹다.

7. 값진 서비스를 위해서라면 기다릴 수 있다.

8. 혼자 기다림은 함께 기다리는 것보다 더 지겹다.

앞서 제시한 대기시간에 대한 환자의 경험의 질을 높이기 위한 3가지 방법; 1) 대기시간의 시각화, 2)시스템 개선에 의한 시간의 단축, 3) Task 제공으로 대기시간에 가치 부여 는 공통적으로 대기시간에 대한 부정적 시각을 제한하고 긍 정적인 시각으로 전환시키고자 한다. 정부의 처방전 전자문 서화 정책이 병원과 약국에서의 프로세스를 단순화 시켜 환 자의 대기시간은 단축시킬 것으로 예상하며, 본 연구에서는 David H. Maister의 지루한 기다림의 유형에 대한 이해를 바탕으로 정부의 처방전 전자문서화 계획에 발맞추어

1. 체감 대기시간을 단축시킬 수 있는 서비스

2. 대기시간에 가치를 부여할 수 있는 서비스

를 디자인 하고자 한다. 이에 먼저 환자가 약국에서 처방전 을 이용해 약을 조제해가는 과정을 조사하고 그 과정에 해 당하는 사용자의 경험과 욕구에 대해 정리해보았다. 다음으 로, 사용자에게 최적화된 서비스 제공 환경 및 툴, 컨텐츠를 구성해보았다.

\section{Waiting Environment at Pharmacy}

\subsection{Waiting area}

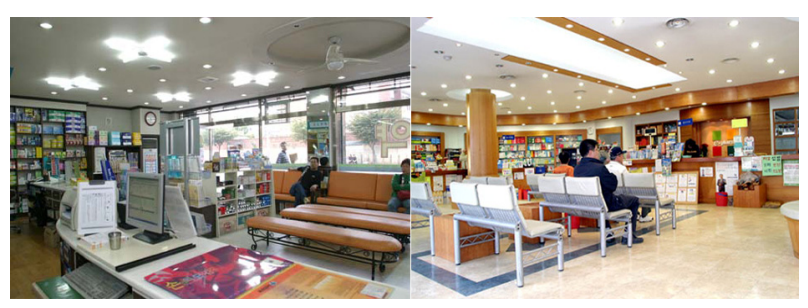

Figure 2. Images of waiting area at pharmacies

일반적으로 약국에서는 백색 타일과 조명, 원목과 가죽을 이용하여 청결함과 따뜻함을 강조하는 인테리어를 선호한다. 하지만 눈부실 정도로 밝은 백색 조명과 반짝이는 타일은 차
갑고 공포스러운 이미지를 주기도 한다. 또한, 환자들이 나 란히 앉을 수 있는 벤치와 소파를 이용하고 전반적인 배치 를 약사와 조제실로 향하게 하여 어떤 인터렉션과 정보가 없는 "맹목적인 기다림"의 분위기를 직접적으로 연출하고 있다.

\subsection{Customer journey map}

일반적인 환자의 Journey map은 다음과 같다.

1) 아픈 곳이 어딘지 간단한 자가진단을 한다. 2) 주변에 관련 병원을 찾는다. 3) 병원에 들어선다. 4) 진료 접수를 한다. 5) 진료 대기한다. 6) 의사에게 진료를 받는다. 7) 처 방 대기한다. 8) 처방전을 받으며 진료비 수납을 한다. 9) 병원을 나선다. 10) 병원 주변 또는 집 근처 약국을 찾는다. 11) 약국을 들어선다. 12) 처방전 접수를 한다. 13) 조제 대 기한다. 14) 처방약을 받으며 조제비를 수납한다. 15) 약국 을 나선다. 16) 식사 후 약을 먹는다.

이번 연구에서는 병원에서 처방전을 받는 순간부터의 의 료 서비스 개선을 위한 것이므로 위 Journey map의 8번 에서 16 번까지의 사용자 경험에 초점을 맞추어 사용자의 Action과 관련 Requirements를 조사하여 보았다. 조사 결 과, Figure 3의 Place에서 A-1. 대기의자와 A-2. 식사 후 과정에서 사용자의 Requirements가 부정적인 감정과 함께 나타났다. A-1의 공간에서는 의도하진 않은 대기시간이 생 기게 되면서 환자가 할 일이 없어지고, 비생산적인 시간을 보내게 된다. 이는 환자의 '아프다'라는 특이사항과 아픈 사 람들이 모인 공간이라는 약국의 특성 때문에 '빨리 집에 가 고 싶다', '다른 사람한테 병을 옮지는 않을까' 등의 부정적인 사고를 갖게 만든다. 부정적인 사고는 대기시간에 대한 체감 시간을 실제 시간보다 상대적으로 길게 느껴지게 유도하기 도 하며, 예기치 않은 대기시간에 의해 환자는 불안, 짜증, 걱정, 우울, 조급 등의 부정적 감정을 느끼게 된다. $\mathrm{A}-2$ 의 공간에서는 사용자가 정확하게 파악하고 있지 않은 Action 을 취해야 하는 상황에 접하게 되면서 다양한 부정적인 생 각을 하게 된다. 물론 조제약을 약사에게 건네 받을 때 간단 한 복용 방법과 약의 종류에 대해 설명을 듣지만, $\mathrm{A}-1$ 의 불 안정한 상황을 벗어나고자 하는 심적 상태에 영향을 받아 집 중력이 떨어질 수 있다. 또한, 익숙하지 않은 정보에 대해 시 각적 근거 없이 청각적인 Input에만 의지한 기억은 지속되 기 힘들다. 또한, 사용자가 아이 엄마일 경우에는 청소년, 일 반인, 노약자들이 처방에 의지하는 태도를 보임과 다르게, 준 전문가 수준의 정보를 원하는 경향을 보였다. $\mathrm{A}-2$ 의 공 간에서도 역시 불안, 초조, 걱정, 짜증, 우울과 같은 부정적 감정을 느끼게 된다. 감기, 알레르기성 질병과 관련하여 의 사들은 평균 이틀 치의 약을 처방을 내리고 재방문을 통해 


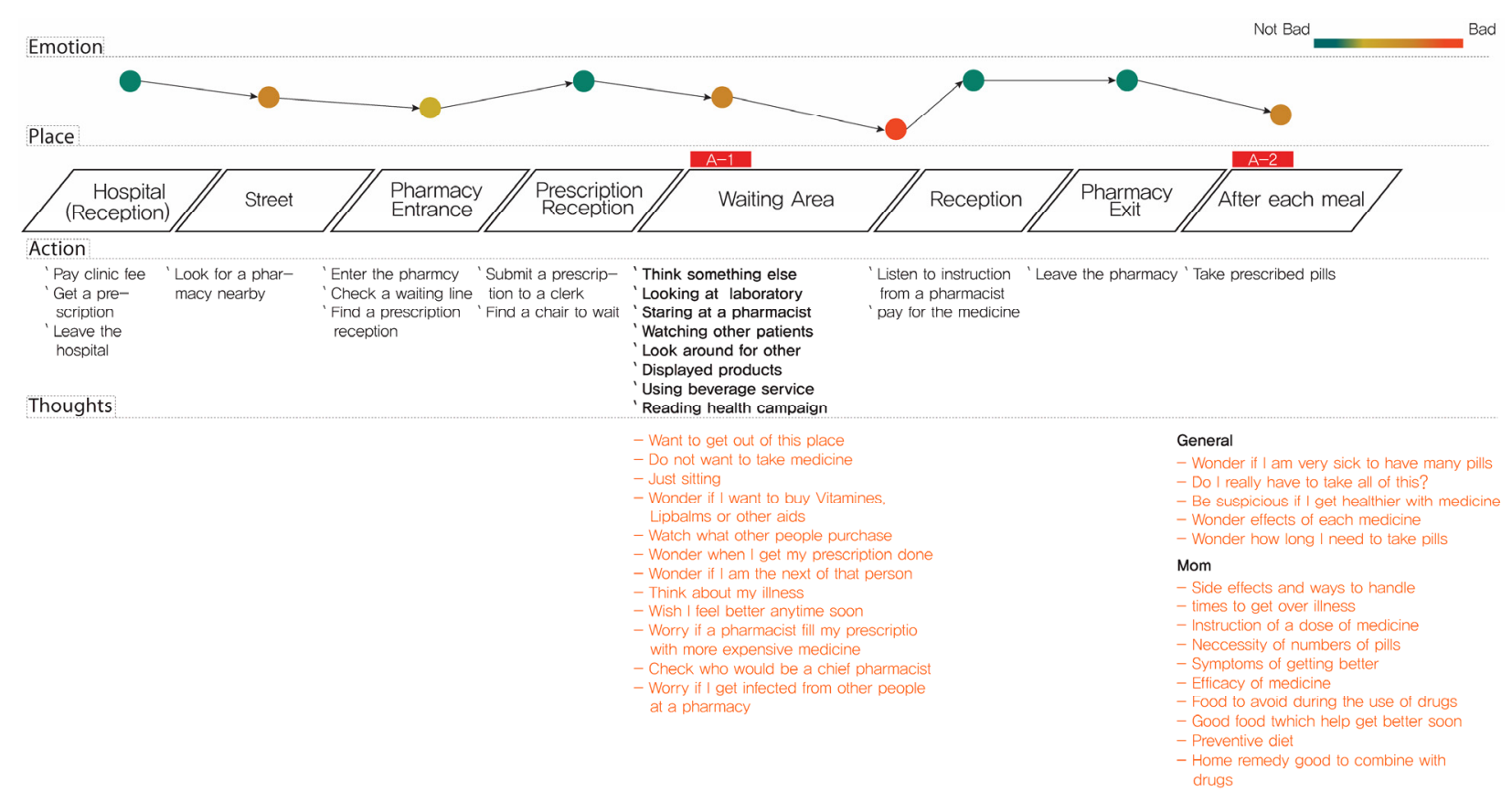

Figure 3. Customer journey map

새로운 처방을 환자에게 권유하지만, 대부분의 환자들은 스 스로 판단하여 병이 호전되고 있다라고 생각되면 투약을 중 단한다고 답변하였다.

\subsection{Medical service case study}

현재 약국에서는 처방전 접수 시 DUR(Drug Utilization Review)라는 시스템을 통해 여러 과에서 처방을 받더라도 중복 또는 상호되는 약을 알려주고, 걸러주는 서비스를 제공 하고 있다. 그리고 대기시간에 실행되고 있는 서비스에는 $\mathrm{TV}$ 시청, 잡지, 기타 건강식품 광고 또는 에너지 드링크를 무료로 제공하는 것이 있다. 또한, 조제 후 제공되는 서비스 에는 처방전의 약의 이름과 수량을 약 봉투에 추가로 기입 하여 주며, 간단히 약사가 복용 방법과 부작용에 대해 구술 로 설명하고 때때로 약 봉투에 손으로 기입해주는 것이 있 다. 그렇게 함으로써 집에 돌아간 후에도 환자가 개인적으로 인터넷으로 약에 관한 검색이 가능하고, 다른 병원 이용 시 에도 유용한 정보로 사용 가능하다. 하지만 약 봉투에 약의 명칭을 기입만으로는 어떻게 생긴 약이 해당 약인지, 어느 제약회사의 제품인지 직관적으로 알기 힘든 문제가 있다. 이 와 관련하여 일본의 한 약국에서는 아래 Figure 4 와 같이 약의 명칭, 이미지, 수량, 복용 방법, 효과, 부작용 등을 자세 하게 A4 용지에 기입하여 약 봉투에 함께 넣어주고 있다. 물론 평균 대기시간은 기본 30 분을 넘지만 수납 시 친절한 설명과 함께 자세히 적인 설명서를 넣어주는 서비스는 고객
으로 하게끔 긴 대기시간이 기다릴 가치가 있다는 인식을 심 어주게 되었고, 재방문 단골 손님을 구축하게 되었다.

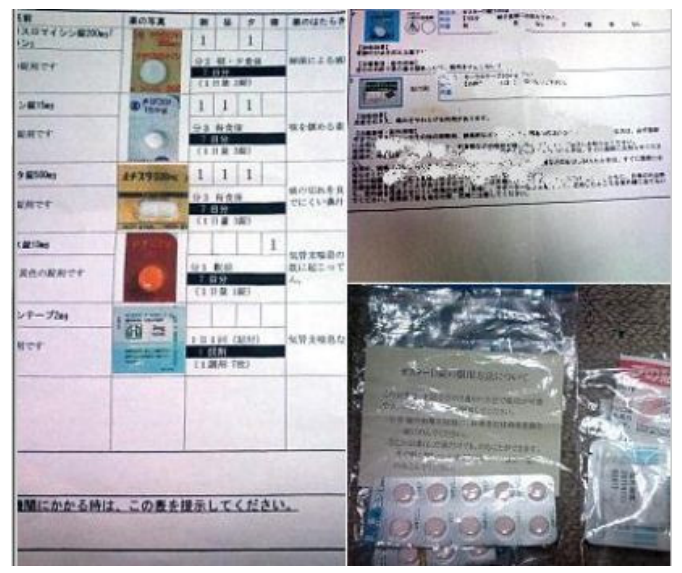

Figure 4. Example of Japanese prescription

\section{4. 'e-prescription' Service Design}

\subsection{Problems}

현재 약국에서의 서비스 디자인 문제

- 짧은 대기시간에 걸 맞는 서비스의 부재 
- 처방 받은 약에 대한 충분한 설명의 부재

- 사용자의 불안한 심리

\subsection{User requirements}

처방된 약에 대한 User Requirements

- 약의 종류별 효능, 제약회사를 알고 싶다.

- 약의 부작용과 대처 방법을 알고 싶다

- 왜 많은 약을 먹어야 하는지 알고 싶다.

- 병이 나아지고 있다는 증상을 알고 싶다.

- 약과 병행할 수 있는 식이요법/민간요법을 알고 싶다.

- 낫고 있다는 증상이 무엇인지 알고 싶다.

- 병의 예방법을 알고 싶다.

약국 대기시간에 관한 User Requirements

- 대기 인원이 몇 명인지 알고 싶다.

- 대기 예상시간을 알고 싶다.

- 조제 받을 약에 대해 알고 싶다.

\subsection{Main goals}

위의 처방 받은 약과 약국에서의 대기시간에 대한 User Requirement를 대기시간 축소를 위한 3가지 방법을 응용하 여 e-prescription service design을 위한 3가지 방향을 정하였다. 1) 대기시간에 대한 시각화와 환자가 알고 싶어하 는 그리고 알아야 하는 정보를 제공함으로써 체감 대기시간 을 감축한다. 2) 환자가 약을 복용함에 있어 필요한 정확하 고 자세한 정보를 전달한다. 3) 체감 대기시간 축소와 정확 한 정보 제공을 통해 환자의 심리적 불안감을 감소시키고, 긍정적인 사고를 유도하여 의사- 환자 - 약사의 신뢰적 관계 를 향상시킨다.

\subsection{Design}

약국을 이용하면서 발생하는 User requirement를 크게 세 가지로 구분하여 우선순위 순으로 정리해 보았다.

1) 예상 대기시간; 사용자가 다른 Task를 할 것인지, 그 낭 기다릴 것인지 판단하게 되는 요인이 된다. 또한 자신이 얼마나 기다려야 하는지 알고 있다면 시간의 경과에 대한 주 의를 좀 덜 기울이게 될 것이고 그로 인해 실제 경과한 시간 보다 더 짧게 지각할 수도 있을 것이다(Lee, 1996). 2) 나 의 처방전; 사용자가 미리 처방 받을 약에 대해 숙지하게 됨으로써 더 궁금한 사항에 대해 정리를 하고, 나을 수 있다 는 의지를 갖게 된다. 3 ) 지난 처방전; 어떠한 약이 달라졌는 지 또는 자신의 건강 상태의 변화를 볼 수 있다.

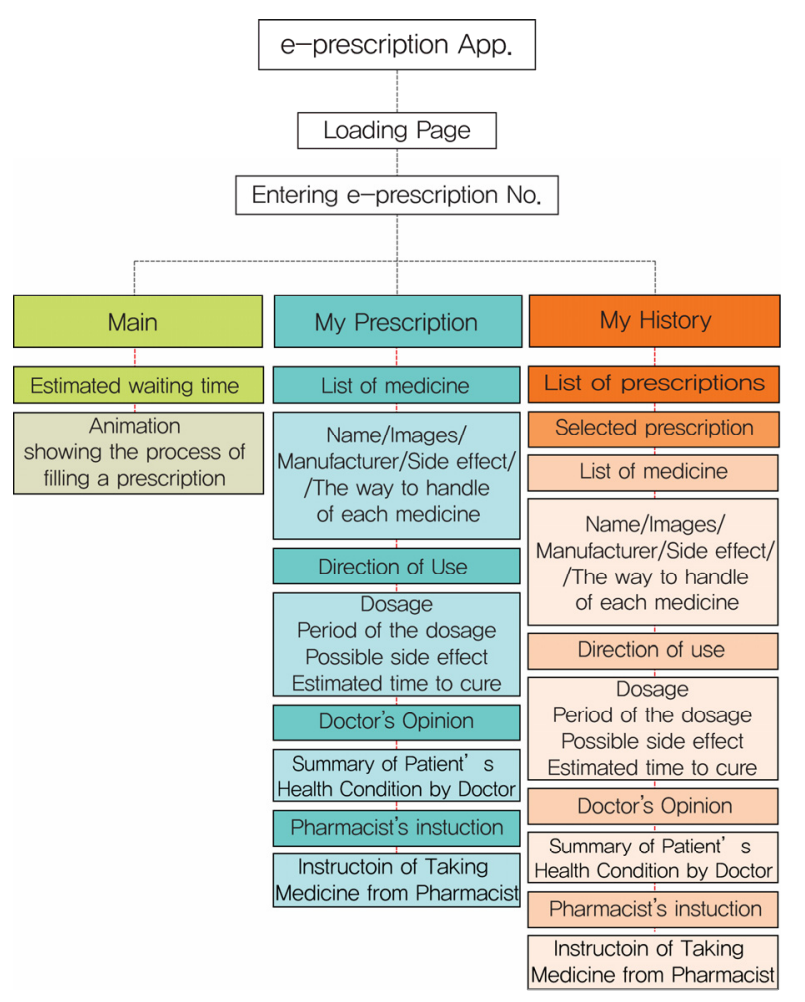

Figure 5. Structure of e-prescription application

최근 Smart phone 사용이 확산되면서 버스 정류장, 지하 철, 은행, 영화관, 커피전문점 등에서 대기시간에 스마트폰을 통한 각종 정보 검색 및 오락, 독서, 학습과 같은 사용자 행 태가 관찰된다. 휴대폰의 경우 개인 소지품으로 1) 2차 감염 에 대한 염려가 없고, 2) 무선 인터넷을 통해 정보 수집이 가능하고, 3) 장소에 구애 받지 않고 사용이 가능하고, 4) 지 속적인 정보보관 및 접근이 가능하여 정보를 개인화할 수 있 다. 이러한 Smart phone의 사용 행태와 장점은 대기시간을 효율적으로 운용하기에 적합하며, 이에 Smart phone을 위 한 e-prescription service application을 제안하고자 한다.

e-prescription application를 사용자가 실행하고 1) 사 용자가 처방전 번호를 입력하면 2) 대기 인원 수를 확인할 수 있다. 사람이 시간의 경과에 더 많은 주의를 기울일 경우 실제로 경과한 시간보다 더 길게 지각될 수 있다. 따라서 시 간의 경과에 주의를 기울이는 것을 방해할 수 있는 어떤 자 극이 주어질 경우, 실제로 경과한 시간보다 더 짧게 지각될 수 있을 것이다(Zakay and Hornik, 1991; Lee, 1996). 서 비스는 소비자가 서비스 전달과정에 참여해야 하는 특성을 가지고 있어서 서비스를 받기 위해 소비자들은 어쩔 수 없이 대기나 지연을 경험하게 되는 경우가 많다( $\mathrm{Sa}, 2009)$. 그 렇기 때문에 예상시간을 보여줄 경우, 상황에 따라 1 분이 정확한 60 초가 되지 않을 경우가 발생하게 되고, 사용자의 

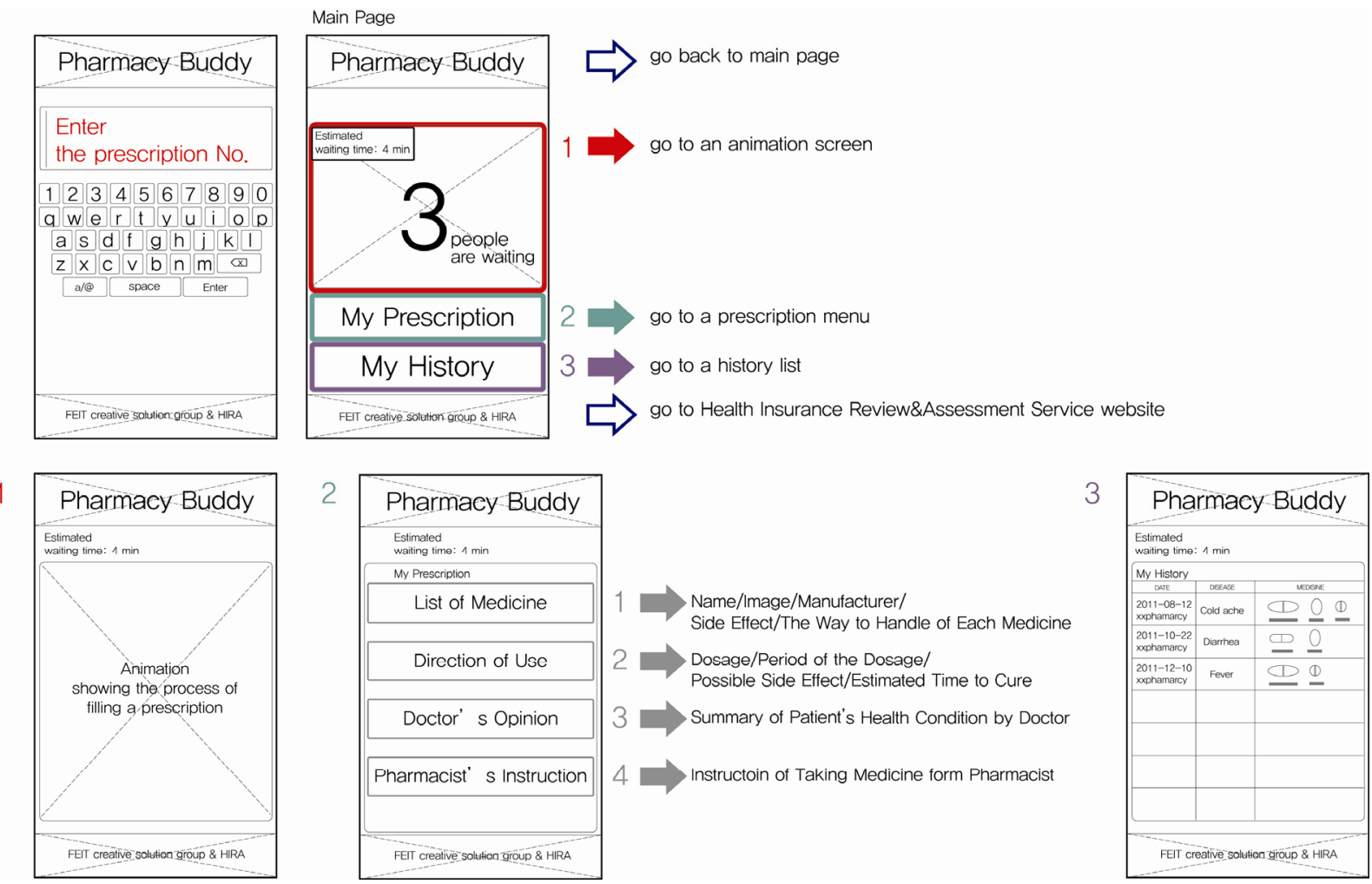

Figure 6. Wireframe of e-prescription application

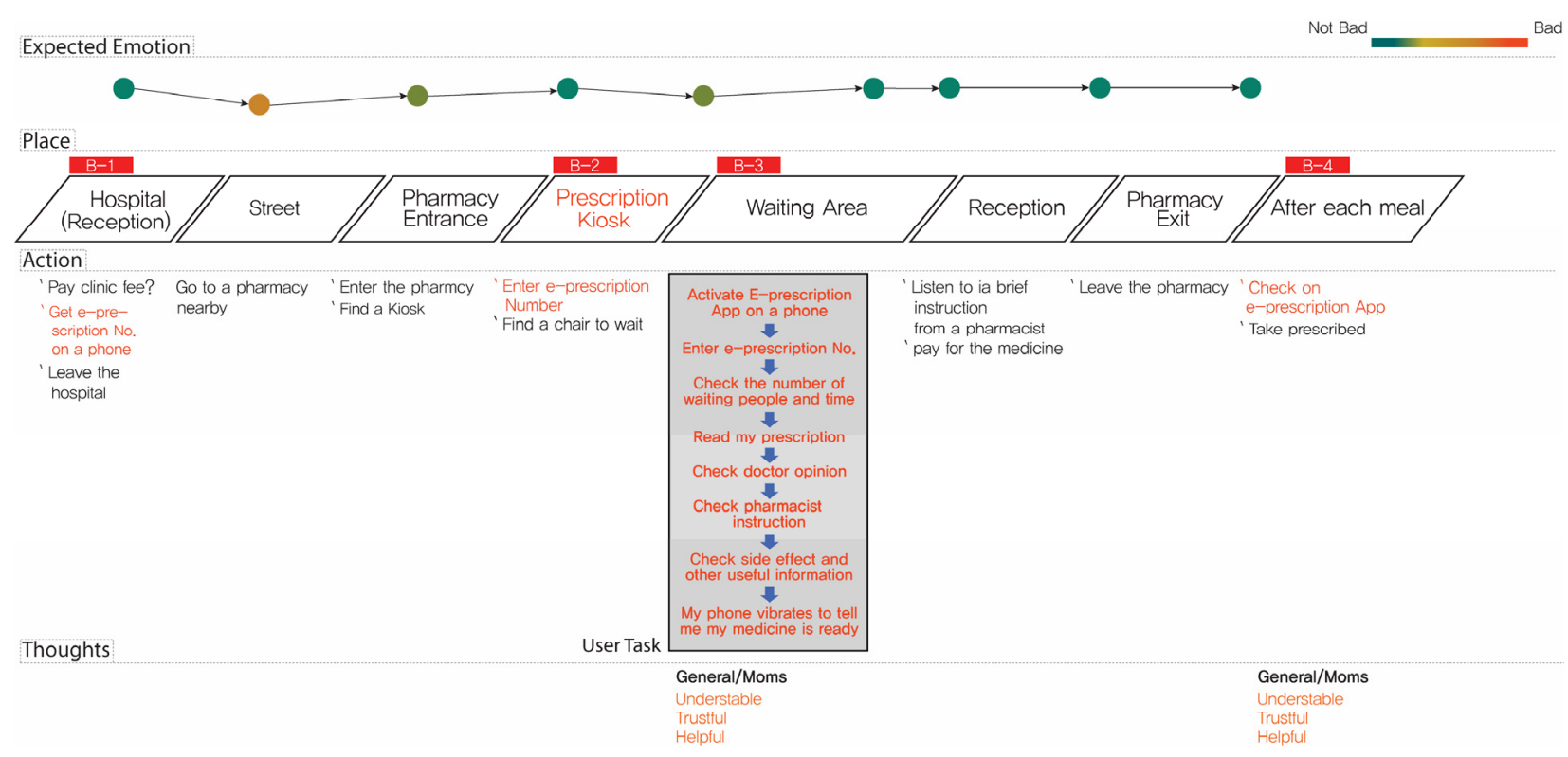

Figure 7. New customer journey map

1 분이라는 시간에 갖는 막연한 신뢰가 깨어지면서 대기의 책임을 서비스 제공자에게 돌리게 된다. 하지만 대기 인원으 로 보여줄 경우, 사용자 자신의 대기 위치를 구려하여 대기
시간을 상대적인 시간 개념으로 계산하기 때문에 체감시간 을 줄일 수가 있다. 3) 나의 처방전 버튼을 클릭하게 되면 처방된 약의 종류가 이미지, 이름, 명사형으로 정리된 효능 
(ex: 해열제, 지사제 etc), 제조회사, 1회 복용량과 함께 리 스트로 정리되어 보인다. 각각의 약을 클릭하면 자세한 효능 과 부작용, 부작용에 대한 대처 방법을 볼 수 있다. 4) 복용 방법을 클릭하게 되면 복용량 및 방법, 복용 기간, 전체적인 부작용 및 대처 방법, 낫기까지 걸리는 예상시간을 확인할 수 있다. 5) 의사 소견을 클릭하면, 병원에서 의사가 환자를 진단한 후 입력한 예상원인, 증상과 같은 의사의 소견을 확 인할 수 있다. 6) 약사의 지시를 클릭하게 되면 약을 복용 하는 기간 내에 주의해야 할 음식, 또는 좋은 음식과 같이 식이요법, 민간요법, 예방법, 복용 후 낫고 있다는 증상 등 처방약에 관련된 설명을 읽을 수 있다.

\section{Results}

e-prescription service를 통하여 사용자는 대기시간을 자신이 받게 될 약에 관한 정보를 미리 숙지하면서 빠른 쾌 유를 위해 노력할 수 있는 방법을 익히면서 보내게 된다. 이 를 통해 사용자는 자신이 처한 상황에 대한 부정적 판단을 하기보다 처방약과 자신의 병에 대해 학습하는 시간을 가지 게 된다. 그리하여 체감 대기시간이 단축됨과 동시에, 정확 하고 세밀한 정보를 바탕으로 자신이 나을 수 있다는 자신 감과 의지, 믿음을 갖게 된다. 또한, 받고 있는 의료 서비스 에 대해 만족을 하게 됨으로써 의사- 환자 - 약사의 신뢰도 가 쌓이게 된다. 즉, $\mathrm{e}$-prescription service는 의료 서비스 를 개선하여 '아프다'라는 환자의 상태를 제외한 간접적인 부 정 요소들을 제한시키면서, 개선된 서비스에 대한 만족도를 높여 긍정적인 감성을 유발하여 '아프다'라는 사용자의 경험 에서 '부정 속 긍정'을 유도할 수 있다.

\section{Conclusion}

현재 병원 및 약국 찾기 또는 진료 상담에 관한 어플리케 이션이 많이 개발되어 있어, 본 연구에서는 병원에서 환자가 처방전을 받는 순간부터의 경험에 초점을 맞춰 진행하였다. 사용자의 경험을 장소 또는 행위로 나누어 보기보다 Context 관점으로 총체적인 경험을 대상으로 한 서비스 디자인이 필 요하다. 이에 의료 서비스 어플리케이션은 예방-상담-병원 및 의사 찾기-병원 접수-대기-진료-처방-수납-약국 찾 기-처방전 접수-대기-수납-복용과 같이 서비스 제공자 위주의 경험을 1) 전체적으로 사용자 위주로 개선시킬 수 있도록 기획되어야 한다. 또한, 다양한 연령층과 문화권의
사용자를 위하여 Universal한 입/출력 디자인이 필요하며, 디자인은 예방-치료-완쾌의 경험을 긍정적으로 이끌어갈 수 있도록 종합적이고 감성적으로 접근되어야 한다.

정부의 처방전 전자문서화 정책은 처방전 번호를 환자의 휴대폰으로 전송하는 시스템으로 처방된 약을 코드화할 수 있는 가능성이 있다. 처방약의 코드화는 나아가 3) 약 조제 과정의 무인화를 고려해볼 수 있게 한다. 약 조제 과정의 무 인화는 심야시간과 휴일에 발생하는 응급 상황 시, 의사와의 화상통화를 통해진단 후 받은 처방전을 조제 받을 수 있는 기회를 열어주게 되어 환자 중심의 새로운 서비스 디자인에 대한 필요성과 관련하여 더 심도 있는 다양한 연구가 이루어 져야 하겠다.

\section{References}

Choi, M. K., Psychology of Waiting Line, http://blog.naver.com/mta_korea /80038385402(retrieved December 12).

Kim, S. B., "Antecedents and Consequences of the Types of Waiting Times in Medical Services", Korean Journal of Hospital Management, 12(2), 69-92, 2007.

Lee, H. J., Elimination of paper prescription till 2013, The Korean Doctors' Weekly, http://doc3.koreahealthlog.com/42871(retrieved December 12).

Lee, Y. J., "The Study on The Impact of Waiting on User's service assessment", Seoul National University Management Journal, 30,3 30,4('96.12), 107-137, 1996.

Sa, B. B., "Influences of Servicescape on Customers' Response in Delay Induced Failure of Healthcare Service", Han Yang University, 2009.

Sohn, D. W., Separation of Prescribing and Dispensing Drugs Starts From Next July, Kyung Hyang Newspaper, http://newslibrary.naver.com/ viewer/index.nhn?articleId=1999091800329102001\&editNo=40\&pr intCount=1\&publishDate=1999-09-18\&officeld=00032\&pageNo=2 $\&$ printNo $=16857 \&$ publishType $=00010$ (retrieved December 15,2011$)$

The Korean Women Pharmacist News, Pharmacy in A Society, http:// www.ikwn.co.kr/(retrieved December 11, 2011).

\section{Author listings}

Dong Min Lee: mick@khu.ac.kr

Highest degree: MFA, 3-D Design, Cranbrook Academy of Art Position title: Professor, Department of Industrial Design, Kyung Hee University

Areas of interest: CD, UI, UX, HCI 
Hye Jung Park: hyejunghennypark@gmail.com

Highest degree: MFA, Department of Furniture Design, Rhode Island School of Design

Position title: Senior Manager, Smart Solution Lab, FEIT Creative

Solution Group

Areas of interest: User Experience, Context Design, $\mathrm{HCI}$

Dong In Lee: arduke@naver.com

Highest degree: MBA, International Business of GPS, Kyung Hee

University

Areas of interest: DM, UI, UX, HCI
Date Received : 2011-12-30

Date Revised :2012-01-16

Date Accepted : 2012-01-21 